\title{
Experimental and Theoretical Investigations on Frost Heave in Porous Media
}

\author{
Feng Ming and Dong-qing Li \\ State Key Laboratory of Frozen Soil Engineering, Cold and Arid Regions Environmental and Engineering Research Institute, \\ Chinese Academy of Sciences, Lanzhou 730000, China \\ Correspondence should be addressed to Dong-qing Li; dqli@lzb.ac.cn
}

Received 28 August 2014; Accepted 24 December 2014

Academic Editor: Gongnan Xie

Copyright (C) 2015 F. Ming and D.-q. Li. This is an open access article distributed under the Creative Commons Attribution License, which permits unrestricted use, distribution, and reproduction in any medium, provided the original work is properly cited.

\begin{abstract}
For the construction in cold regions, frost heave and thaw settlement are the two factors which must be taken care of. Considered that a saturated soil column was subjected to an overburden pressure to model the ice lens growing process. A typical process, which coupled water, heat, and stress that happened in a saturated freezing soil column, was simulated by the finite element software. We did the numerical simulation under the same conditions as the experiment tests and then compared the results from temperature, frost heave, frozen structure, water content, and water intake. Result shows that the simulation results match well with the experimental results, and the correctness of the mathematical model is validated. On that basis, frost heave amount under different conditions by changing the temperature boundary and loading boundary is obtained. The frost heave has an optimum temperature gradient. Under the optimum value, the frost heave amount increases with increasing temperature gradient. Above the optimum value, frost heave decreases with increasing temperature gradient. Increasing the overburden pressure, frost heave amount always decreases. These results can provide references for the constrictions in cold regions.
\end{abstract}

\section{Introduction}

The study on frost heave is always a hot subject in the frozen soil research field. There is a great difference in frost heave characteristics for different kinds of soils. The main destructive aspects of frost action in freezing soil are frost heave and thaw weakening. Frost heave refers to the volume expansion when a soil freezes. Significant frost heave is usually due to the water transfer and accumulation. In the meantime, frost heave is responsible for the thaw weakening. Frost heave damage of porous media in cold regions is well known [1]. Thus, it is crucial to study and predict frost heave of freezing soil.

The phenomenon of frost heave has been noted since the late 17th century. In recent century, people did much work on frost heave. Studies on frost action in soils flourished in 1960s to 1980s. The first explanation of frost heave was based on the capillary theory, which was proposed by Sill and Skapski [2]. In the capillary theory, capillary suction at the ice-water interface in frozen fringe was taken as the driving force of moisture migration. According to unfrozen water dynamics, a model which considered the phase change and water migration was built [3]. Guymon and Luthin [4] through computation found Harlan model could well predict water migration but could not predict frost heave. Taylor and Luthin [5] ignored the term of convection and heat transfer and simplified Harlan model. They believed that the soil produces frost heave when the volume of ice content exceeded $85 \%$ of the porosity. Frost heave is a process of coupling water, heat, and stress that interact in essence. Shen and Ladanyi [6] presented a model which coupled the stressstrain behavior of the frozen soil to heat and mass transport and frost heave was estimated by summation of the volume expansion due to the ice segregation, at last the numeric analysis was executed on computer. Li et al. [7] established a frost heave model which coupled heat-moisture-mechanic. Furthermore, Chen et al. [8] considered the interaction of ice water, gas, and soil grain and established the theoretical frame of multiphase porous medium for the freezing soil. These models mentioned above can predict the frost heave and water migration, but none of them considered the ice lens. 
With deepened understanding of frost heave, a number of works have investigated the development of models to predict frost heave that include the ice lens formation. Gilpin [9] established a model for the prediction of ice lens and frost heave in soils by assuming quasi-steady temperature. O'Neill and Miller [10] established the rigid ice model which can explain the formation and development of ice lenses. Nixon [11] used discrete ice lens theory for frost heave in soils. Cao et al. [12], based on equilibrium of phase and force, established an ice segregating model for saturated granular soil and gave the numerical simulation results of $1 \mathrm{D}$ saturated granular soil freezing process. All these models were without considering the effect of overburden loading. Thomas et al. [13] investigated the thermo-hydro-mechanical behavior of soils and presented a model which could simulate the processes of soil freezing and ice segregation, but the judge criterion for the formation of ice lens is not clear. Zhou and Li [14] established a mathematical model for coupled water, heat, and stress fields. The model can predict temperature, water content, frost heave, and ice lenses but lack experimental verification. A complete frost heave model consists of five parts, coupled water and heat transfers, formation of ice lenses, model parameters determination, solution technique, and experimental verification. Thus, many frost heave models have been proposed in the past to describe this process, but none of them has been generally accepted.

In this paper, a completely frost heave model was presented, and the separating porosity ratio was taken as the judge criterion for the formation of ice lens. A typical process, which coupled water and heat transfer that happened in a saturated freezing soil column, was simulated by the finite element software (COMSOL). Using indoor one-dimension frost heave experiments, we demonstrate the reliability of the mathematical model. Through the numerical simulation, we analyzed the dynamic balance between the frost heave amount and overburden pressure and temperature gradient. The main objective of this study is to develop an effective method to estimate frost heave amount for engineering purposes.

\section{System of Theoretical Model}

Mathematical description of frost heave requires modeling of heat transfer, water migration, and ice lens growth in freezing soil. In the following section, these components are presented.

2.1. Basic Assumptions. Consider a saturated salt-free soil column subjected to an overburden pressure, as shown in Figure 1. The growing ice lens is included in the frozen zone. The following assumptions are considered to simplify the complex coupling of water, temperature, and stress.

(1) Soil column is elastic, homogenous, and isotropic.

(2) Moisture migration is in liquid form, without considering the migration of ice crystals.

(3) Soil grain and ice cannot be compressed and ignore the ice pressure melting.

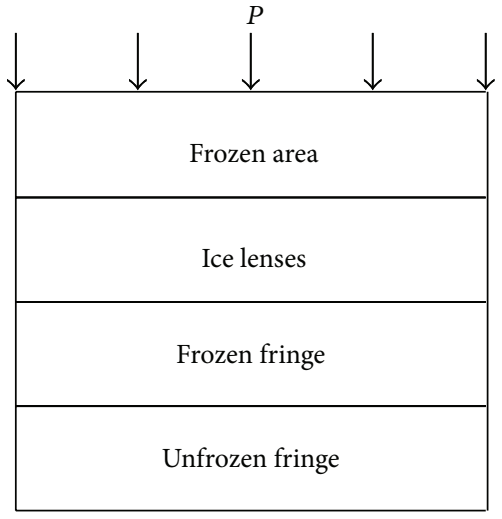

Figure 1: Structure of soil sample.

(4) Moisture migration obeys Darcy's law and the permeability is constant in the unfrozen area.

Top-down freezing tests for the soil columns were conducted in an open system with overburden pressure, as shown in Figure 1. The top temperature was lower than the freezing temperature and the bottom temperature was higher than the freezing temperature. At the base plate, there was a tube which was used to supply water from the outside. From Figure 1, it can be seen that the soil column can be divided into four parts, from top to bottom, which are frozen area, ice lenses, freeze fringe, and unfrozen area, respectively.

In freezing soil, $S_{i}$ is the volume of ice content, which can be written as [15]

$$
S_{i}= \begin{cases}1-\left[1-\left(T-T_{0}\right)\right]^{\alpha} & T \leq T_{0} \\ 0 & T>T_{0}\end{cases}
$$

where $T$ is temperature, $T_{0}$ is the freezing point of pure water, both in Celsius temperature, and $\alpha$ is experimental parameter.

2.2. Moisture Migration. Soil water potential $\psi$ is the main power of moisture migration in soil; it consists of many potential energies. In saturate system, soil water potential $\psi$ can be written as

$$
\psi=P_{w}+G
$$

where $P_{w}$ is water pressure; $G$ is gravitational potential.

Pore pressure equals the weight sum of pore ice pressure and pore water pressure [10]; it can be described as

$$
P_{\text {por }}=\chi P_{w}+(1-\chi) P_{i},
$$

where $\chi$ is a coefficient, which can be expressed as $\chi=$ $\left(1-S_{i}\right)^{1.5}$.

As it is hard to solve $P_{i}$, then the Clapeyron equation is used to describe the relationship among temperature, water pressure, and ice pressure when ice and water coexist in phase equilibrium $[16,17]$ :

$$
\frac{P_{w}^{\prime}}{\rho_{w}}-\frac{P_{i}^{\prime}}{\rho_{i}}=L \ln \left(\frac{T^{\prime}}{T_{0}^{\prime}}\right) .
$$


Rearranging (4), we obtain

$$
P_{w}^{\prime}=\frac{\rho_{w}}{\rho_{i}} P_{i}^{\prime}+L \rho_{w} \ln \left(\frac{T^{\prime}}{T_{0}^{\prime}}\right),
$$

where $L$ is the latent heat of fusion; $P_{w}^{\prime}$ and $P_{i}^{\prime}$ are the absolute pressure of pore water and pore ice, respectively; $T^{\prime}$ is Kelvin temperature; $T_{0}^{\prime}$ is the freezing temperature in Kelvin temperature.

Here,

$$
\begin{gathered}
P_{w}^{\prime}=P_{w}+P_{a}, \\
P_{i}^{\prime}=P_{i}+P_{a}, \\
T^{\prime}=T+T_{0}^{\prime},
\end{gathered}
$$

where $P_{w}$ and $P_{i}$ are the gauge pressures of pore water and ice, respectively; $P_{a}$ is atmospheric pressure; $T$ is Celsius temperature.

Substituting (6) into (5),

$$
P_{w}=\frac{\rho_{w}}{\rho_{i}} P_{i}+\left(\frac{\rho_{w}}{\rho_{i}}-1\right) P_{a}+L \rho_{w} \ln \left(\frac{T+T_{0}^{\prime}}{T_{0}^{\prime}}\right) .
$$

Uniting (3) and (7), $P_{i}$ can be eliminated, so pore pressure is expressed as

$$
\begin{aligned}
P_{w}= & \frac{(1-\chi)\left(\rho_{w}-\rho_{i}\right) P_{a}}{(1-\chi) \rho_{i}+\chi \rho_{w}} \\
& +\frac{(1-\chi) \rho_{i} \rho_{w} L \ln \left((T+273) / T_{0}\right)}{(1-\chi) \rho_{i}+\chi \rho_{w}} \\
& +\frac{\rho_{w} P_{\text {por }}}{(1-\chi) \rho_{i}+\chi \rho_{w}} .
\end{aligned}
$$

Ignoring the gravitational potential, the soil water potential can be express as

$$
\psi=P_{w} .
$$

From (9), it can be seen that temperature and external pressure are the main factors influencing the moisture migration.

According to the assumptions, we can get the equation of thermal diffusion and water migration. A detail of the deduction process was presented by Zhou and Li [14].

Equation of thermal diffusion is

$$
\begin{gathered}
\left(C-\frac{L \rho_{i} e}{1+e} \frac{\partial S_{i}}{\partial T}\right) \frac{\partial T}{\partial t}-\frac{L \rho_{i} S_{i}}{1+e} \frac{\partial e}{\partial t} \\
=\frac{\partial}{\partial x}\left(\lambda \frac{\partial T}{\partial x}\right)+C_{w} k \frac{\partial \psi}{\partial x} \frac{\partial T}{\partial x} .
\end{gathered}
$$

Equation of water migration is

$$
\begin{gathered}
\frac{\rho_{i} S_{i}+\rho_{w}\left(1-S_{i}\right)}{\rho_{w}(1+e)} \frac{\partial e}{\partial t}+\frac{e\left(\rho_{i}-\rho_{w}\right)}{\rho_{w}(1+e)} \frac{\partial S_{i}}{\partial T} \frac{\partial T}{\partial t} \\
=\frac{\partial}{\partial x}\left(k \frac{\partial \psi}{\partial x}\right) .
\end{gathered}
$$

2.3. Ice Lens Formation. A stress criterion for initiating a new ice lens is adopted by many researchers [9-11] to determine when and where a new ice lens forms. O'Neill [18] thought that when the pore pressure exceeded the total pressure, as the effect stress was zero, the ice lens forms. This method considers that in a one-dimensional case the soil skeleton separates and a new ice lens forms when the pore pressure exceeds the sum of the overburden stress and the separation strength of the freezing soil

$$
P_{\text {por }} \geq \sigma+P_{\text {sep }}
$$

where $P_{\text {sep }}$ is separation strength.

In this paper, the stress criterion approach defined by (12) has been adopted. For typical freezing situations $P_{\text {sep }}$ is in the range $20 \sim 150 \mathrm{kPa}$ [11]; in the paper $P_{\text {sep }}=50 \mathrm{kPa}$. It has also been observed that, immediately after a new ice lens is initiated, the local pore pressure falls to the sum of overburden stress and separation strength $[11,19]$.

Consequently, we can express $P_{\text {por }}$ as [14]

$$
P_{\text {por }}=\int_{x}^{l}\left(\gamma-\gamma_{0}\right) \mathrm{d} x_{0}+E_{s} \frac{e-e_{0}}{1+e_{0}} .
$$

To be able to judge the formation of ice lenses by void ratio directly, the concept of separating void ratio was presented. When the void ratio is greater than or equal to $e_{\text {sep }}$, ice grains connect to each other to become integrated and ice lenses begin to form. A judge criterion for the format ion of ice lenses in terms of porosity ratio can be expressed as

$$
e \geq e_{\text {sep }}
$$

Equaling (12) and (13), the critical void ratio $e_{\text {sep }}$ can be expressed as

$$
e_{\text {sep }}=\frac{1+e_{0}}{E_{s}}\left(\sigma+P_{\text {sep }}-\int_{x}^{l}\left(\gamma-\gamma_{0}\right) \mathrm{d} x_{0}\right)+e_{0} .
$$

Equations (10) and (11) constitute the water-heat transfer equations. Equation (14) can be used to judge whether the ice lens formed or not.

2.4. Frost Heave. According to the soil compression curve, the following formula can be got:

$$
d e=\frac{1+e_{0}}{E_{S}} d \sigma
$$

In one dimension, the relationship between strain and porosity ratio can be described as

$$
\varepsilon=\frac{e-e_{0}}{1+e_{0}}
$$

The relationship between displacement $u$ and strain $\varepsilon$ can be written as

$$
\frac{\mathrm{d} u}{\mathrm{~d} x}=\varepsilon
$$




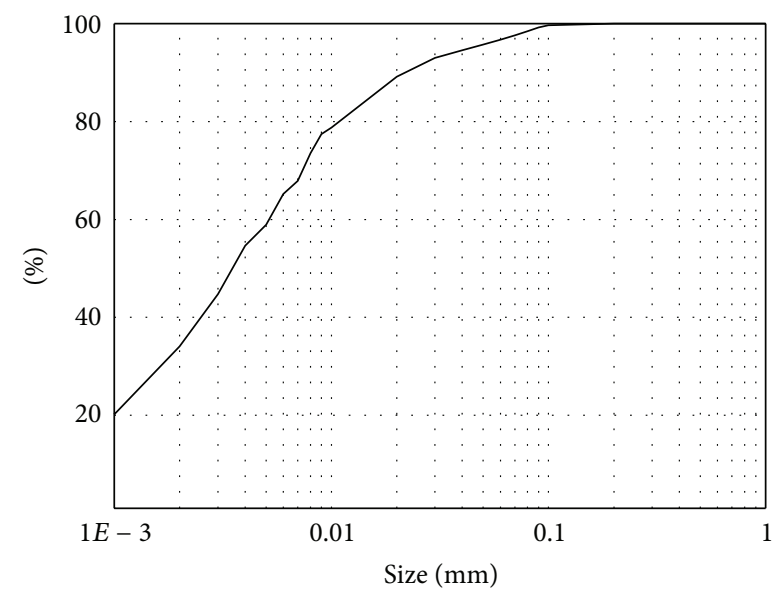

FIgURE 2: Grain size distribution of studied Qinghai-Tibet clay.

As the displacement at the bottom of soil column is zero, solving (18), we obtain

$$
u=\int_{0}^{x} \varepsilon \mathrm{d} x_{0} .
$$

Substituting (17) into (19) and gives

$$
u=\int_{0}^{x} \frac{e-e_{0}}{1+e_{0}} \mathrm{~d} x_{0} .
$$

Thus, the amount of frost heave can be obtained by the following formula:

$$
\Delta H=u(l) .
$$

\section{Model Experiment Application of Model to Typical Conditions}

3.1. Equipment and Material of Experiment. The equipment of experiment was freeze-thaw cycling test chamber. The experimental system contained refrigerating system, temperature control system, water pump system, data collection system, and other assistant facilities. The unidirectional freezing tests were conducted in the open system. The QinghaiTibet clay was used in the experiments and the grain size distribution was shown by Figure 2 .

The soils were mixed with distilled water to obtain a water content of $17 \%$ and with a dry density of $1.69 \sim 1.71 \mathrm{~g} / \mathrm{cm}^{3}$. The soil sample was made into columns, $10.1 \mathrm{~cm}$ in diameter and $10.0 \mathrm{~cm}$ in height. Ten thermistors were placed in the side of the wall of the cylindrical cell to measure the temperature distribution in the soil simple. Before the test, the sample was put into a thermotank with a constant temperature at $3^{\circ} \mathrm{C}$ for $24 \mathrm{~h}$ to allow the temperature equilibrium. Then the top plate temperature was changed to $-3^{\circ} \mathrm{C}$ and the base plate temperature was kept at $3^{\circ} \mathrm{C}$. Its side wall was heatisolated and flow-isolated, and a load of $100 \mathrm{kPa}$ was put on the top plate. In order to measure the amount of frost heave, a displacement meter was placed on the top end of the soil sample. Water was applied freely at the warm end.

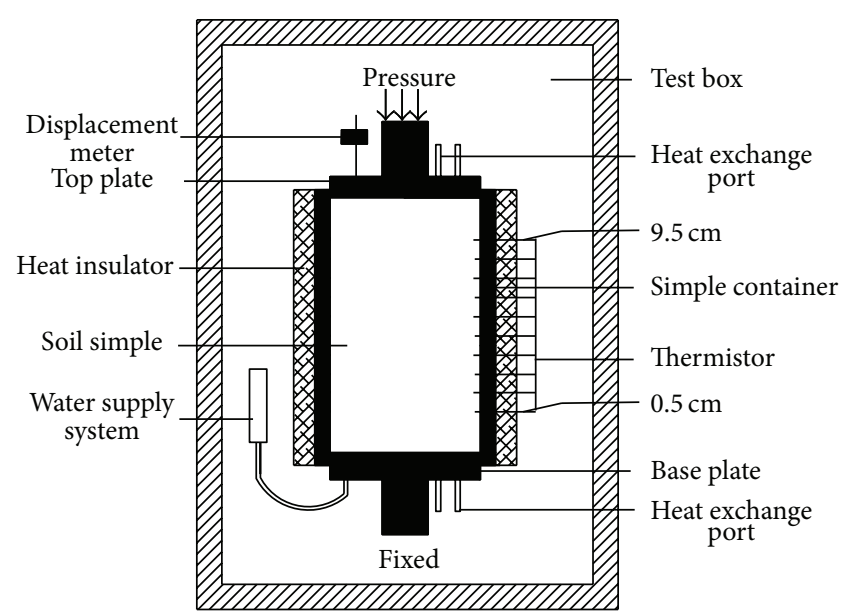

FIGURE 3: Sketch of experimental apparatus.

The temperature profile and total heave were monitored by DT80 data collection system, every 5 seconds collected once. Water intake was recorded by manpower. The freezing test lasted for $72 \mathrm{~h}$. Finally, the sample was photographed and cut down into layers with a thickness of $1 \mathrm{~cm}$ for water content determination after testing.

Figure 3 shows the sketch of experimental apparatus.

3.2. Numerical Simulation. The condition of numerical simulation was the same as experiment. The initial conditions and boundaries were as follows: $\left.u\right|_{x=0}=0,\left.e\right|_{x=0}=0.46,\left.e\right|_{x=0.10}=$ $0.5,\left.T\right|_{x=0}=3^{\circ} \mathrm{C},\left.T\right|_{x=0.10}=3^{\circ} \mathrm{C},\left.e\right|_{t=0}=0.46$, and $\left.T\right|_{t=0}=$ $3^{\circ} \mathrm{C}$. This problem was solved by the COMSOL Multiphysics simulation software; 120 quadric-Lagrange elements were generated, a time step of 3 minutes was adopted, and the total computation time was 72 hours. The soil thermophysical properties were measured in the laboratory. The ice content was given by Tice et al. [15]. The permeability value of thaw was measured in the laboratory. The parameters and their values were shown in Table 1.

The one-dimensional ice lens growth hypothesis assumes that all the water at the base of the growing ice lens migrates from the unfrozen soil through the partially frozen soil in the frozen fringe. Experiments on the hydraulic conductivity of partially frozen soils have shown that the permeability decreases rapidly as soon as pore ice forms. In freezing soil, hydraulic conductivity was a function of temperature $[9,10]$. After the ice lens formed, the ice lens will play a role of aquiclude and the water cannot flow through the ice lens; thus we adjust the hydraulic conductivity as

$$
k= \begin{cases}k_{0}\left[1-\left(T-T_{0}\right)\right]^{\beta} & x<x_{s} \\ 0 & x<x_{s} .\end{cases}
$$

Here, $k_{0}$ is the hydraulic conductivity of unfrozen soil; $\beta$ is a coefficient; the suggested value is $\beta=-8 ; x_{s}$ is the position where an ice lens forms. 
TABLE 1: Parameters and values.

\begin{tabular}{|c|c|c|c|c|c|}
\hline Parameter & Value & Parameter & Value & Parameter & Value \\
\hline$\alpha$ & -5 & $\rho_{i}\left(10^{3} \mathrm{~kg} \cdot \mathrm{m}^{-3}\right)$ & 0.917 & $C_{s}\left(\mathrm{~kJ} \cdot \mathrm{m}^{-3} \cdot \mathrm{K}^{-1}\right)$ & 2260 \\
\hline$\beta$ & -8 & $\rho_{w}\left(10^{3} \mathrm{~kg} \cdot \mathrm{m}^{-3}\right)$ & 0.98 & $C_{i}\left(\mathrm{~kJ} \cdot \mathrm{m}^{-3} \cdot \mathrm{K}^{-1}\right)$ & 1874 \\
\hline$E_{s}(\mathrm{MPa})$ & 2.5 & $g\left(\mathrm{~N} \cdot \mathrm{kg}^{-1}\right)$ & 9.81 & $C_{w}\left(\mathrm{~kJ} \cdot \mathrm{m}^{-3} \cdot \mathrm{K}^{-1}\right)$ & 4180 \\
\hline$k_{0}\left(10^{-8} \mathrm{~cm} \cdot \mathrm{s}^{-1}\right)$ & 1.7 & $\lambda_{s}\left(\mathrm{~J} \cdot \mathrm{h}^{-1} \cdot \mathrm{m}^{-1} \cdot \mathrm{K}^{-1}\right)$ & 4320 & $L\left(\mathrm{~kJ} \cdot \mathrm{kg}^{-1}\right)$ & 334.56 \\
\hline$P_{a}(\mathrm{kPa})$ & 101 & $\lambda_{i}\left(\mathrm{~J} \cdot \mathrm{h}^{-1} \cdot \mathrm{m}^{-1} \cdot \mathrm{K}^{-1}\right)$ & 7992 & $e_{\text {sep }}$ & 1.5 \\
\hline$\rho_{s}\left(10^{3} \mathrm{~kg} \cdot \mathrm{m}^{-3}\right)$ & 2.72 & $\lambda_{w}\left(\mathrm{~J} \cdot \mathrm{h}^{-1} \cdot \mathrm{m}^{-1} \cdot \mathrm{K}^{-1}\right)$ & 2088 & $T_{0}\left({ }^{\circ} \mathrm{C}\right)$ & 0 \\
\hline
\end{tabular}

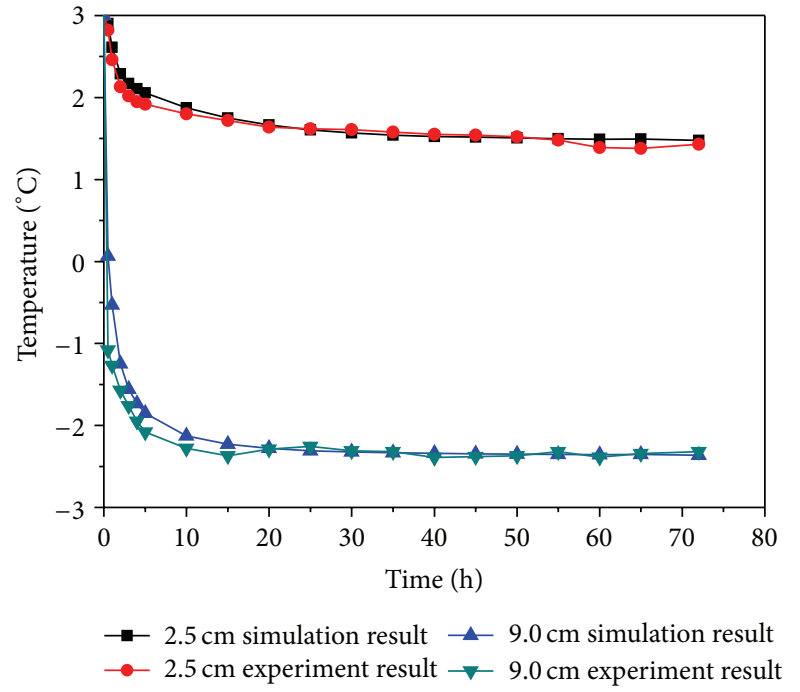

FIGURE 4: Temperature versus time at different position.

\section{Results and Discussion}

Given the initial conditions, boundaries, and other needed parameters, the equations could be solved. In order to verify the validity of the mathematical model, we took the experiment with the top plate temperature at $-3^{\circ} \mathrm{C}$, the bottom temperature at $3^{\circ} \mathrm{C}$, and a load of $100 \mathrm{kPa}$ on the top plate, for example, and compared the simulation results with the experimental results.

\subsection{Numerical and Experimental Results Analysis}

4.1.1. Temperature Change. Figure 4 shows the temperatures measured by the thermistors during the experiment. At time zero, the top temperature was changed to minus and the freezing front began to advance in the sample. From Figure 4, it can be seen that the temperature changes rapidly at the beginning of freezing time $(0 \sim 10 \mathrm{~h})$ and then to a steady level $(10 \sim 72 \mathrm{~h})$. It can be seen that temperatures at different positions have the similar change law, but decreasing ratio and cooling amplitude are different (Figure 4); this is similar to results presented by Konrad and Lemieux [20]. The point of $9.5 \mathrm{~cm}$ is near the cold side, and at this point temperature decreases rapidly compared to another point. From this, it can be seen that temperature changes more rapidly near the cold side than further away from the cold side. The temperature of

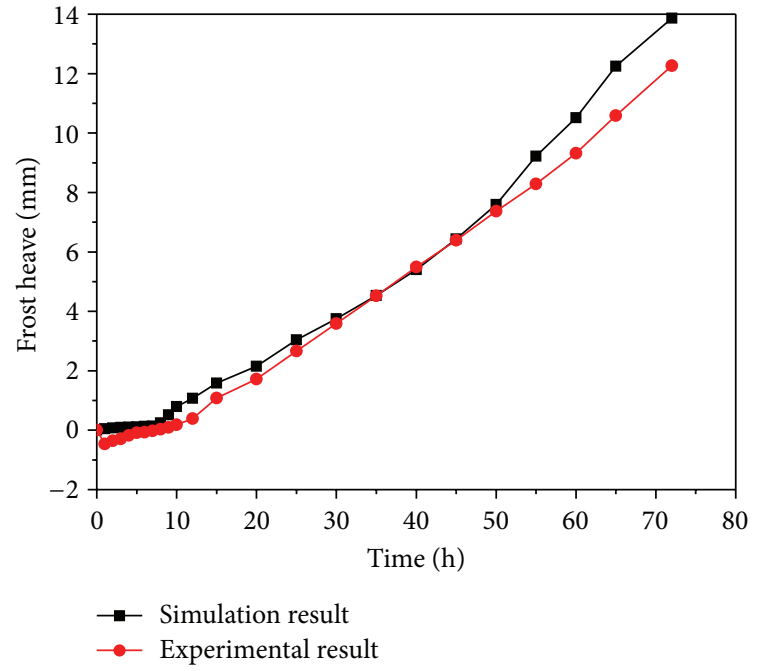

FIgURE 5: Comparison of frost heave between simulation and experiment.

cold side needs $10 \mathrm{~h}$ to descend to a steady level and the warm side needs about $35 \mathrm{~h}$. This shows the temperature changes to a steady level at different positions need different times; it can be concluded that the further the distance to the cold side is, the more the time the temperature will take to decrease to a steady value is. Furthermore, the temperature at the steady level does not means unchanged, but existed a little fluctuation.

4.1.2. Frost Heave. When a sudden temperature constant below freezing temperature is applied to the top end of the soil column, unsteady heat flow is formed. As a frozen front advanced into the soil, pore water freezes in situ and unfrozen water is drawn up to the frozen front; then a volume expansion can be generally observed. This phenomenon is known as frost heave.

Figure 5 is the frost heave comparison between simulation result and experiment result. In the early stage (0 $10 \mathrm{~h}$ ), the soil sample of experiment is compressed. This phenomenon has two reasons: one is shrinkage deformation which is caused by the temperature, and another is the water that was extracted out from the soil sample caused by the consolidation. Until the unfrozen water phase changes and fulfills the pore, the sample can have an obvious deformation. During the frozen fringe moving, the complex process shrinkage deformation and frost heave still are carried out 


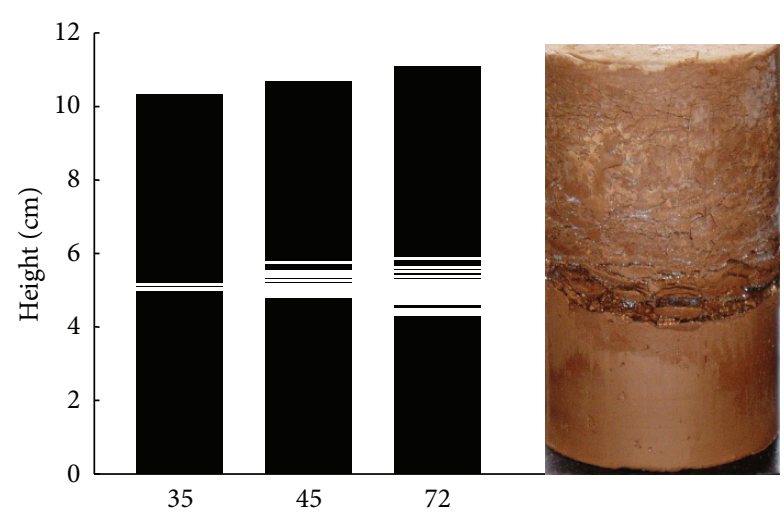

(h)

FIGURE 6: Histogram of ice lenses distribution at different times (the white parts are ice lenses; the right picture is the experimental result after freezing $72 \mathrm{~h}$ ).

in the sample. As seen in Figure 4, almost $10 \mathrm{~h}$, the temperature gradient becomes steady; in the meantime, frost heave amount increases gradually (Figure 5). At the beginning of the test, as the rate of frozen front penetration is high, it does not allow water to migrate and accumulate at a given local for enough time; thus the frost heave amount is small. With the rate of frozen front penetration decreasing, water is allowed to accumulate for enough time and form ice lens. This indicates that the heave due to the freezing of in situ water contributes only a small part of the total heave [19]. Compared to the experimental data with the simulating results, the two frost heave curves have a similar change trend and little difference on value; this shows the proposed model is reliable and the parameters are right.

4.1.3. Ice Lens Distribution. The freezing tests clearly demonstrated that ice lens growth is not a simple one-dimensional process, but rather more complex. The predicted ice lens distributions are illustrated in Figure 6; the white and grey parts of the column represent ice lenses and the soils, respectively. The experimental result of the soil structure after freezing $72 \mathrm{~h}$ also shows in Figure 6. It can be seen that ice strings are distributed horizontally and vertically to the direction of the heat flow (Figure 6), which is similar to results presented by Azmatch et al. [21]. From Figure 6, it can be seen that the position of the ice lens is at the $1 / 2$ height of the soil sample. This is due to the fact that, on one hand, with the increasing of freezing depth, the freezing rate decreases, and it ensures being capable of pumping adequate water from the bottom to form ice lens. On the other hand, with the freezing depth increasing, the velocity of soil heat turnover decreases rapidly and thus is not conducive to form ice lens at a deeper place. Two kinds of reason balance result in this phenomenon.

At the beginning of the test, the freezing front advances downwards rapidly (Figure 4), due to the high thermal gradient near the cold end, and there is not sufficient time for water migration and formation of visible ice lenses, although ice lenses are initiated. Before $35 \mathrm{~h}$, the height of soil column

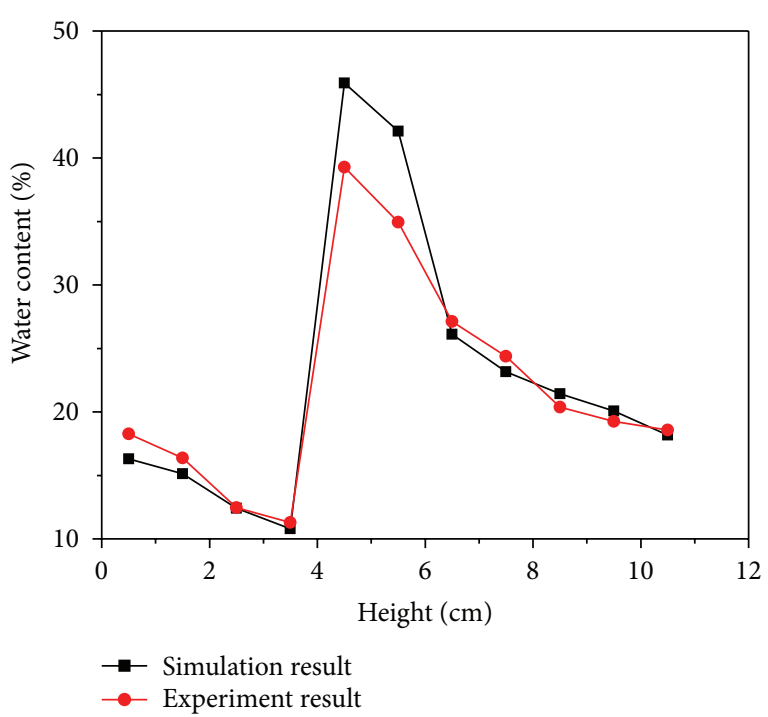

FIGURE 7: Distribution of water content at different position.

is increasing, but no visible ice lenses formed. Thus, the cryogenic structure is the massive type. As the rate of the frozen front penetration decreases, as a consequence of the decreasing thermal gradient, water in unfrozen zone has enough time to transfer to frozen zone and form ice crystals. This results in the pore pressure increase. When the pore pressure reaches $\sigma+P_{\text {sep }}$, a new ice lens is initiated in the frozen fringe according to the stress criterion. As time goes by, larger ice lenses at a greater spacing form progressively in the column and the frost heave increases. The numerical analysis agrees with the experiment results. Such predicted ice lens distributions are consistent with experimental observations in step-freezing tests [22], whose cold and warm sides are maintained at constant temperatures during the complete test.

4.1.4. Water Content. Frost heave is a process caused by transfer of water and freezing. Ice lenses grow, fed by the water moving to the frozen fringe from the unfrozen area by the cryogenic suction. The soil sample was photographed and cut down into layers with a thickness of $1 \mathrm{~cm}$ to obtain water content after the freezing test. The distribution of water content is shown in Figure 7.

It can be seen that the water content decreases in the unfrozen zone $(0 \sim 4 \mathrm{~cm})$ and increases in the frozen zone (4 $11.5 \mathrm{~cm}$ ) (Figure 7). Water content is not distributed smoothly along the column; it distributes with vibration. Around the ice lens formed zone $(4 \sim 6 \mathrm{~cm})$, water content increases more obviously, thus, the maximum water content concentrate at the height of $4 \sim 6 \mathrm{~cm}$. When a temperature gradient is formed between the frozen and unfrozen zones, a suction gradient develops in the frozen zone in response to any temperature gradient and water migrates from the unfrozen soil through the continuous unfrozen water films into the frozen zone. Due to the large rate of freezing front penetration, less water migrates in the upper area. As the rate of freezing front penetration decreases, more water transferred from 


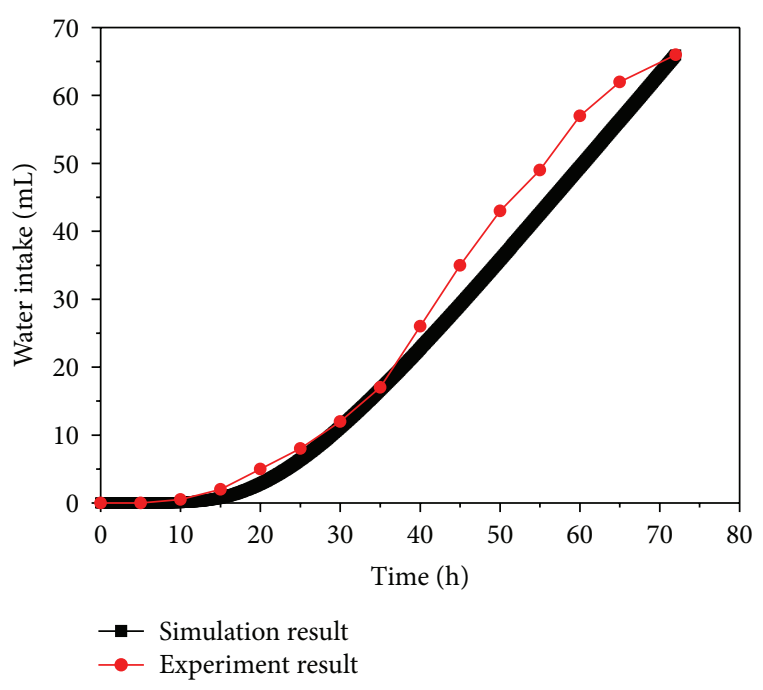

Figure 8: Water intake versus time.

the unfrozen area, as a consequence of the increasing water content. This shows that, during the soil freezing process, the process of dehydration in the unfrozen area and water absorption in the frozen area is carried out in the sample.

4.1.5. Water Intake. As indicated in the previous section, the increase of soil volume is mainly due to the water migration from the unfrozen area of the soil towards the freezing front. Figure 8 shows the result of water intake.

As it can be seen from Figure 8, water intake does not occur immediately at the beginning of the test; this is what agrees with other results [23]. At $10 \mathrm{~h}$, the temperature gradient becomes steady (Figure 4), and the soil sample begins to absorb water. At $35 \mathrm{~h}$, flux rate of water intake increases significantly, mainly due to ice lens formed. Flux rate becomes larger and rises up to a peak value before $35 \mathrm{~h}$. With the temperature gradient gradually becoming stabilization, the flux rate decreases, but the water intake is still increasing. Figure 8 shows the simulation results tally well with the experimental results.

\subsection{Relationship between Frost Heave and Load and Tem-} perature Gradient. In the preceding section a mathematical model of frost heave and ice lensing in saturated soil was present and verified against the experimental data. Therefore, the model can be used to do a series of calculations with the relevant calculation parameters, in order to analyze the influence of overburden pressure and temperature gradient on frost heave.

4.2.1. Different Temperature with Same Pressure. We further explore the effect of temperatures on frost heave. When keeping other conditions unchanged, only changing the temperature of top plate, then we can obtain the frost heave amount (Figure 9). Frost heaving has an optimum temperature gradient as shown in Figure 9. When the temperature gradient is under the optimum temperature gradient, the

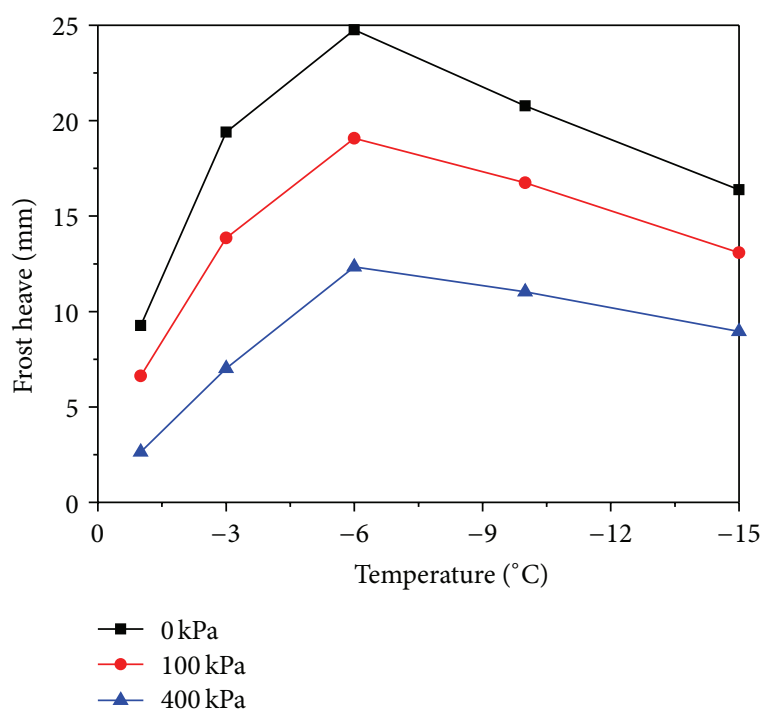

FIgURE 9: Frost heave with different temperature boundary.

frost heaving amount is increased with increasing temperature gradient. When the temperature gradient is above the optimum temperature gradient, the frost heaving amount is decreased with increasing temperature gradient.

As the temperature gradient increases, as a consequent of increasing rate of water intake, the frost heave increases. In addition, increasing temperature gradient reduces the thickness of frozen fringe and increases frost heave. Continuing to increase temperature gradient, owing to the large rate of freezing front penetration, results in the moisture not being able to migrate in time and generates in situ freeze. Thus, the frost heave amount is smaller. Regardless of the temperature gradient, the frost heaving amount decreases with increasing overburden pressure. Therefore, when using the freezing method for constructions, provided that a reasonable temperature gradient and overburden pressure were applied, frost heave can be effectively controlled. It can reduce the impact on the project as well as the surrounding environment.

4.2.2. Different Pressures with the Same Temperature Gradient. With the same temperature gradient, the overburden pressure was changed in turns, $0 \mathrm{kPa}, 50 \mathrm{kPa}, 100 \mathrm{kPa}, 200 \mathrm{kPa}$, and $400 \mathrm{kPa}$, respectively, and then we can obtain the frost heave amount. The result is shown in Figure 10.

When the temperature condition is the same, the frost heaves under different pressures are different (Figure 10). At the first part of the curve, increasing the overburden pressures can decrease the frost heave amount obviously. But, in the second part of the curve, the increasing of overburden pressure does not have an obvious function to decrease the frost heave amount. Thus, in a practical application, we should consider the real situation and allow the frost heave to exist. In a word, the frost heave decreases with increasing overburden pressure, but different temperature has a different changing rate. The effect of overburden pressure on frost heave was also studied by Penner and Ueda [24] in a series 


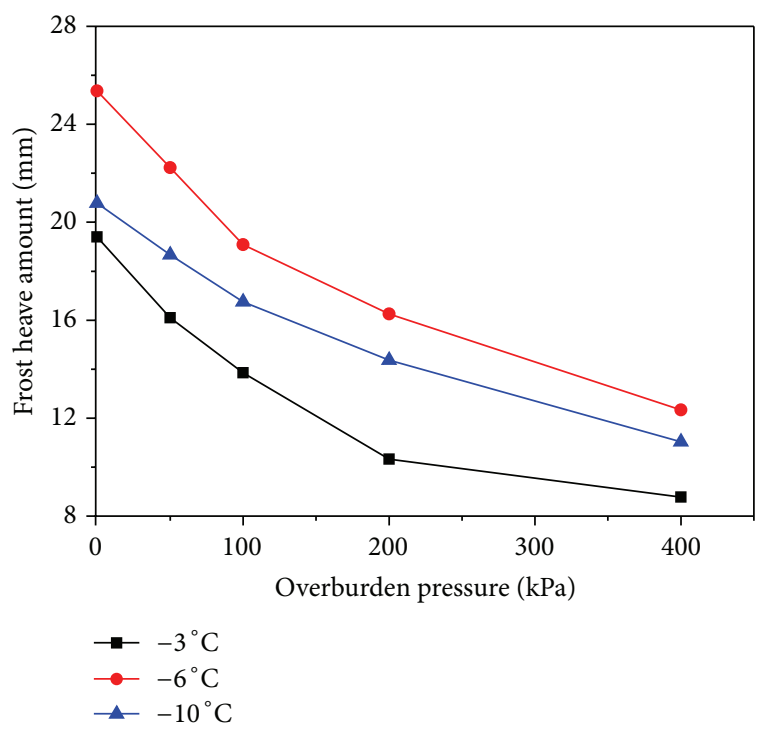

FIGURE 10: Frost heave amount with different pressures.

of unidirectional freezing tests and their experimental results still support this view. The frost heave amount decreases approximately as exponential function of overburden pressure. With the method of fitting, the relationship between frost heave amount and overburden pressure can be described as

$$
\begin{aligned}
&-1{ }^{\circ} \mathrm{C}: u=8.7528 e^{-3.226 P}, \\
& \text { correlation coefficient: } R^{2}=0.9471 ; \\
&-3^{\circ} \mathrm{C}: \quad u=17.593 e^{-1.945 P}, \\
& \text { correlation coefficient: } R^{2}=0.9067 ; \\
&-6^{\circ} \mathrm{C}: \quad u=24.029 e^{-1.749 P}, \\
& \quad \text { correlation coefficient: } R^{2}=0.9717 ; \\
&-10^{\circ} \mathrm{C}: \quad u=20.125 e^{-1.553 P}, \\
& \quad \text { correlation coefficient: } R^{2}=0.9881 ; \\
&-15^{\circ} \mathrm{C}: \quad u=15.792 e^{-1.498 P}, \\
& \text { correlation coefficient: } R^{2}=0.9705,
\end{aligned}
$$

where $u$ is frost heave amount, $\mathrm{mm}$; $P$ is overburden pressure, $\mathrm{MPa}$.

The effect of overburden pressure on frost heave is twofold. Firstly, the pore water pressure beneath the final ice lens is reduced by an amount equal to $\rho_{w}\left(P+P_{\text {sep }}\right) /((1-$ $\chi) \rho_{i}+\chi \rho_{w}$ ) (after the ice lens formed, the pore pressure equals the sum of overburden pressure and segregation strength), the rate of water migration and the rate of frost heave were decreased. Secondly, as the overburden pressure increases, the initiation condition of ice lens becomes more difficult (according to (12)); as a consequent of the thickening frozen fringe, fewer ice lenses formed.

Uniting (23) (27), the relationship between frost heave and overburden pressures can be described as

$$
u=A e^{B P}
$$

where $A$ and $B$ are coefficients, relevant to the temperature gradient.

As mentioned above, the value of $A$ has a peak value which corresponds to the optimum temperature gradient. So when using the method of fitting, the step function should be applied to describe it.

\section{Conclusions}

Based on the law of conservation of mass, the law of conservation of energy, and the static balance condition, a mathematical model of coupled water and heat was established and the model was verified by the experimental results. A series of frost heave tests and numerical simulations have been conducted under different temperature gradients and different overburden pressures. From the above analysis, the following conclusions can be drawn based on this study.

(1) The frost heave model has been verified by the laboratory tests. The compared results have shown that the frost heave amount, temperature, and water intake are generally in agreement with the experimental results and laid the foundation for the calculation of ice lens and frost heave.

(2) Frost heaving has an optimum temperature gradient. Under the threshold, frost heaving amount increases with increasing temperature gradient. Above the threshold value, frost heaving amount decreases with increasing temperature gradient. Frost heaving amount decreases with increasing overburden pressure.

(3) The driving force of moisture migration directly affects the frost heave amount; through adjusting overburden pressure and temperature gradient, driving force can be decreased, thereby decreasing the moisture migration amount. Thus, the frost heave can be effectively controlled.

(4) The focus in this work has been on ice lens and frost heave characteristics in porous media. Freeze-thaw action, which is also referred to as ice lens growth or frost shattering. Frost damage is mainly caused by crack propagation under frost heaving force. Thus, much of the frost damage that occurs in crack rocks and other cohesive materials can be traced to the same underlying physical mechanisms.

\section{Conflict of Interests}

The authors declare that there is no conflict of interests regarding the publication of this paper. 


\section{Acknowledgments}

This research was supported by the National Natural Science Foundation of China (41271080), the Western Project Program of the Chinese Academy of Sciences (KZCX2XB3-19), the Funding of the State Key Laboratory Frozen Soil Engineering (SKLFSE-ZQ-35), and the National key Basic Research Program of China (973 Program) (no. 2012CB026102).

\section{References}

[1] O. B. Andersland and B. Ladanyi, Frozen Ground Engineering, John Wiley \& Sons, Hoboken, NJ, USA, 2nd edition, 2004.

[2] R. C. Sill and A. S. Skapski, "Method for the determination of the surface tension of solids, from their melting points in thin wedges," The Journal of Chemical Physics, vol. 24, no. 4, pp. 644651, 1956.

[3] R. L. Harlan, "Analysis of coupled heat-fluid transport in partially frozen soil," Water Resources Research, vol. 9, no. 5, pp. 1314-1323, 1973.

[4] G. L. Guymon and J. N. Luthin, "A coupled heat and moisture transport model for arctic soils," Water Resources Research, vol. 10, no. 5, pp. 995-1001, 1974.

[5] G. S. Taylor and J. N. Luthin, "A model for coupled heat and moisture transfer during soil freezing," Canadian Geotechnical Journal, vol. 15, no. 4, pp. 548-555, 1978.

[6] M. Shen and B. Ladanyi, "Modelling of coupled heat, moisture and stress field in freezing soil," Cold Regions Science and Technology, vol. 14, no. 3, pp. 237-246, 1987.

[7] N. Li, B. Chen, F. Chen, and X. Xu, "The coupled heat-moisturemechanic model of the frozen soil," Cold Regions Science and Technology, vol. 31, no. 3, pp. 199-205, 2000.

[8] F. X. Chen, N. Li, and G. D. Cheng, "The theoretical frame of multi-phase porous medium for the freezing soil," Chinese Journal of Geotechnical Engineering, vol. 24, no. 2, pp. 213-217, 2002.

[9] R. R. Gilpin, "A model for the prediction of ice lensing and frost heave in soils," Water Resources Research, vol. 16, no. 5, pp. 918930, 1980.

[10] K. O'Neill and R. D. Miller, "Exploration of a rigid ice model of frost heave," Water Resources Research, vol. 21, no. 3, pp. 281-296, 1985.

[11] J. F. Nixon, "Discrete ice lens theory for frost heave in soils," Canadian Geotechnical Journal, vol. 28, no. 6, pp. 843-859, 1991.

[12] H. Z. Cao, S. Liu, F. Jiang, and J. Liu, "The theoretical study on frost heave for saturated granular soil-numerical simulation of $1-\mathrm{d}$ ice segregating model based on equilibrium of force and phase," Chinese Journal of Theoretical and Applied Mechanics, vol. 39, no. 6, pp. 848-857, 2007.

[13] H. R. Thomas, P. Cleall, Y. C. Li, C. Harris, and M. KernLuetschg, "Modelling of cryogenic processes in permafrost and seasonally frozen soils," Geotechnique, vol. 59, no. 3, pp. 173-184, 2009.

[14] J. Z. Zhou and D. Q. Li, "Numerical analysis of coupled water, heat and stress in saturated freezing soil," Cold Regions Science and Technology, vol. 72, pp. 43-49, 2012.

[15] A. R. Tice, D. M. Anderson, and A. Banin, The Prediction of Unfrozen Water Contents in Frozen Soils from Liquid Limit Determinations, Cold Regions Research \& Engineering Laboratory, U.S. Army Corps of Engineers, 1976.
[16] P. B. Black, Applications of the Clapeyron Equation to Water and Ice in Porous Media, Cold Regions Research \& Engineering Laboratory, US Army Corps of Engineers, 1995.

[17] F. X. Chen, Z. P. Song, and N. Li, "Study on moisture migrating force model of freezing soil base on adsorption-film moisture migration mechanism," Journal of Water Resources and Architectural Engineering, vol. 4, no. 3, pp. 1-4, 2006.

[18] K. O'Neill, "The physics of mathematical frost heave models: a review," Cold Regions Science and Technology, vol. 6, no. 3, pp. 275-291, 1983.

[19] J.-M. Konrad and N. R. Morgenstern, "A mechanistic theory of ice lens formation in fine-grained soils," Canadian Geotechnical Journal, vol. 17, no. 4, pp. 473-486, 1980.

[20] J.-M. Konrad and N. Lemieux, "Influence of fines on frost heave characteristics of a well-graded base-course material," Canadian Geotechnical Journal, vol. 42, no. 2, pp. 515-527, 2005.

[21] T. F. Azmatch, D. C. Sego, L. U. Arenson, and K. W. Biggar, "Tensile strength and stress-strain behaviour of Devon silt under frozen fringe conditions," Cold Regions Science and Technology, vol. 68, no. 1-2, pp. 85-90, 2011.

[22] J.-M. Konrad, "Sixteenth Canadian geotechnical colloquium: frost heave in soils: concepts and engineering," Canadian Geotechnical Journal, vol. 31, no. 2, pp. 223-245, 1994.

[23] X. Z. Xu and Y. S. Deng, Experimental Study on Water Migration in Freezing and Frozen Soils, Science Press, Beijing, China, 1991.

[24] E. Penner and T. Ueda, "The dependence of frost heaving on load application-preliminary results," in Proceedings of the International Symposium on Frost Action in Soils, vol. 1, pp. 137143, Luleå University of Technology, Lulea, Sweden, April 1977. 


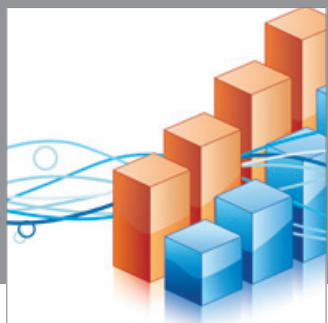

Advances in

Operations Research

mansans

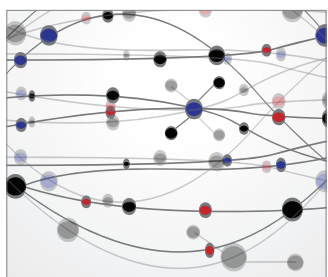

The Scientific World Journal
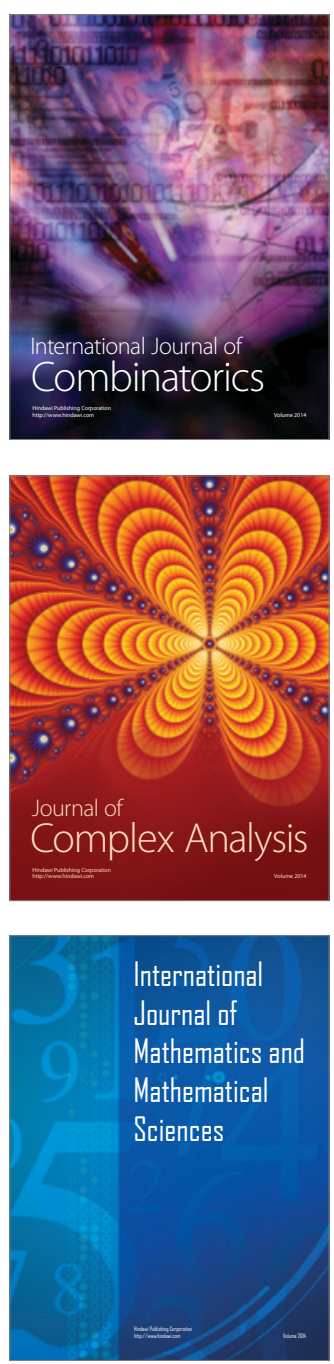
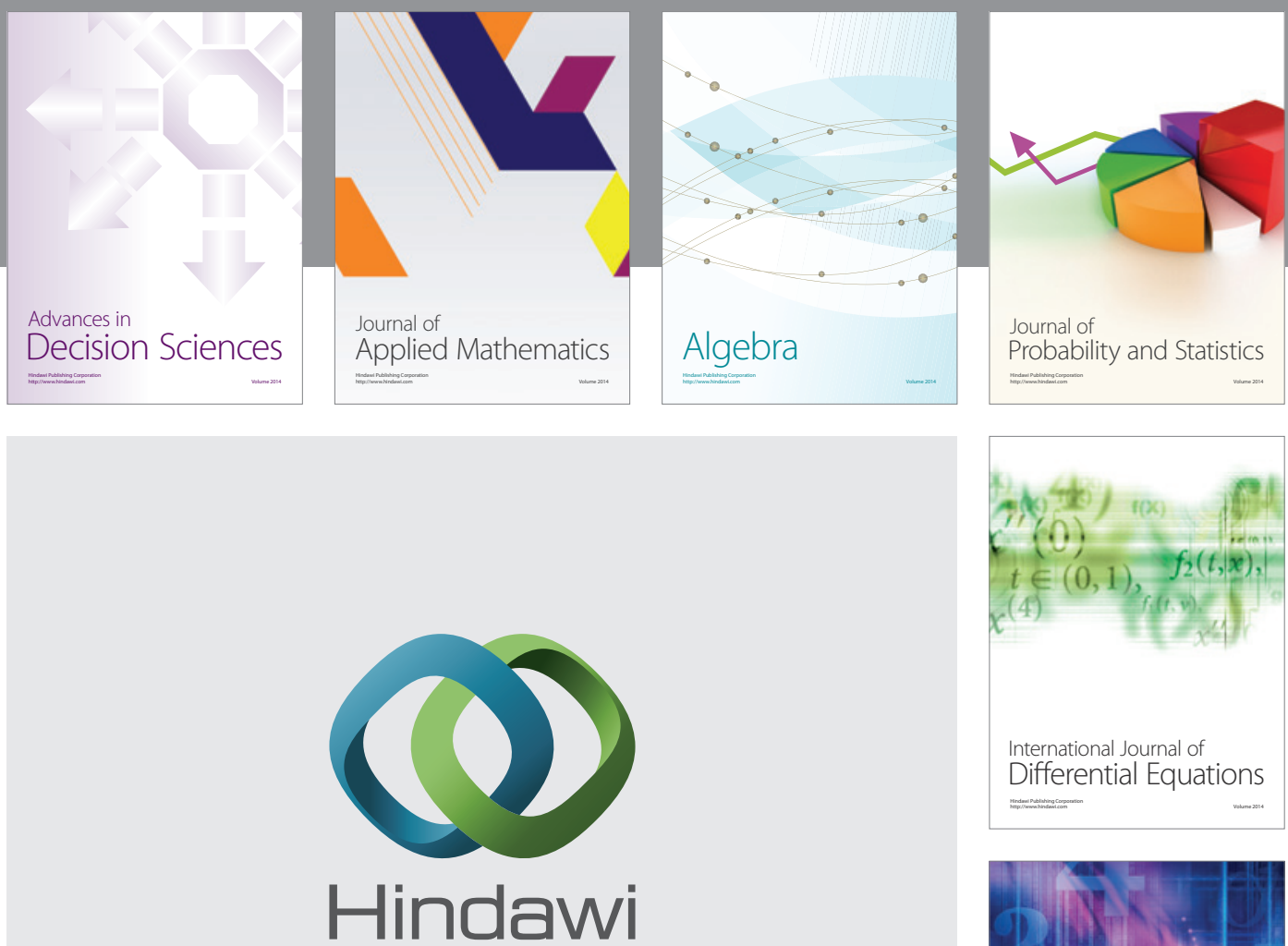

Submit your manuscripts at http://www.hindawi.com
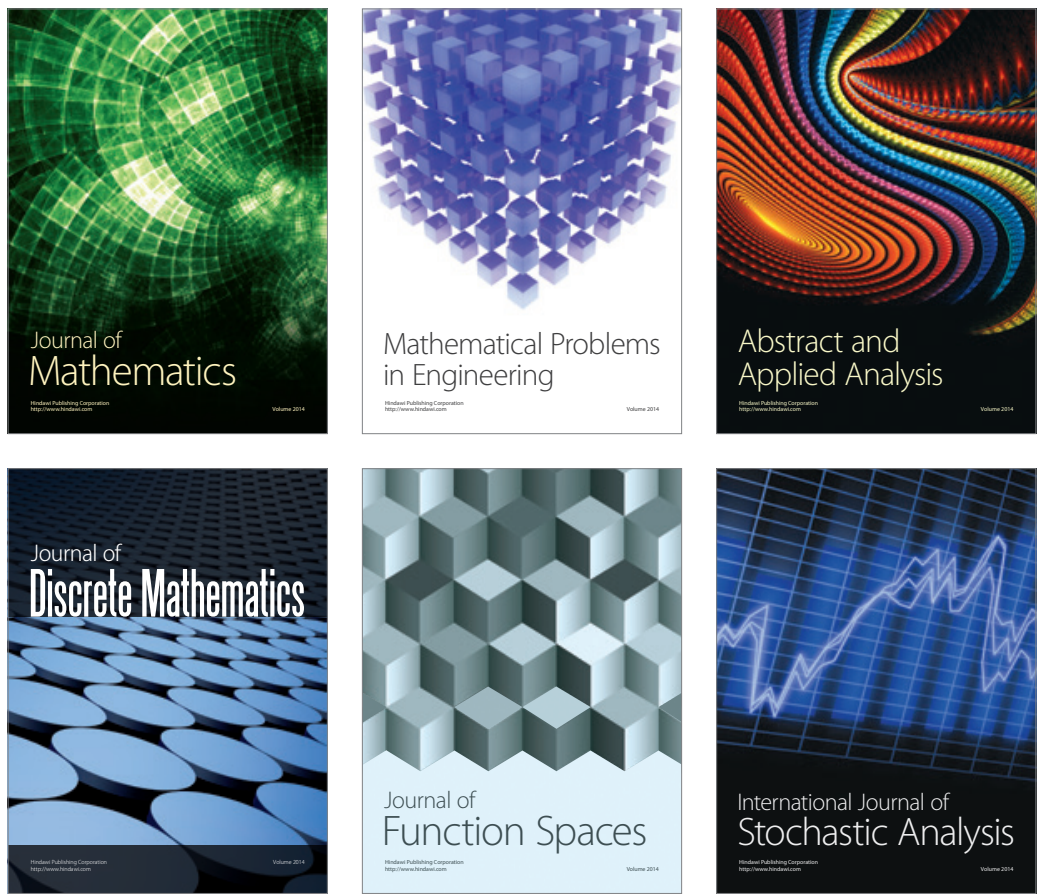

Journal of

Function Spaces

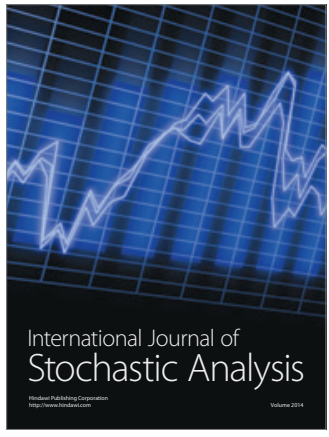

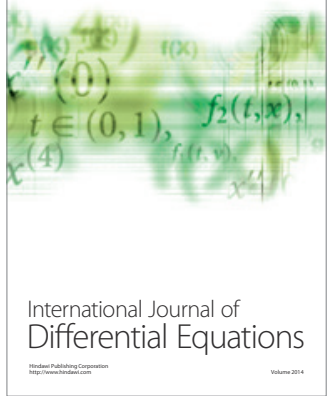
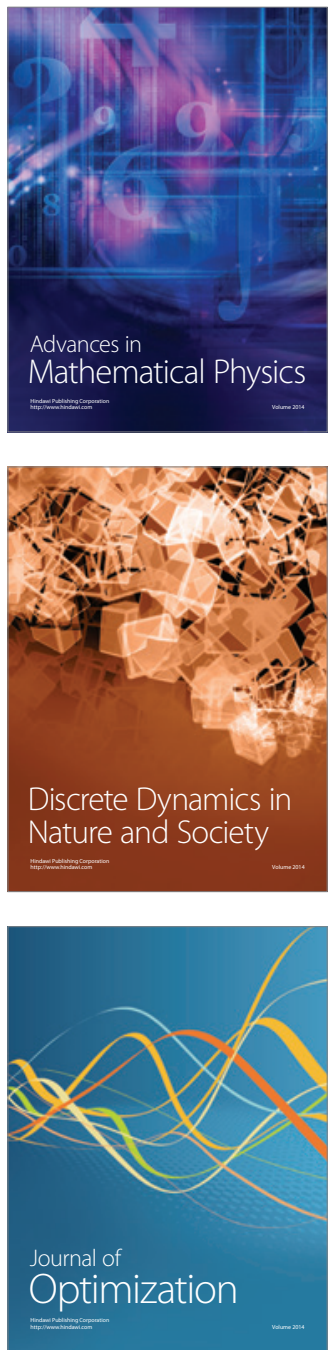